\title{
María Bjerg. Lazos rotos. La inmigración, el matrimonio y las emociones en la Argentina entre los siglos XIX \\ y XX. Bernal: Universidad Nacional de Quilmes, 2019, $125 \mathrm{pp}$.
}

Fátima Alvez ${ }^{\star}$

a inmigración implica desafios y esfuerzos que suelen redundar en una mejora Lpara los inmigrantes y sus seres queridos; si bien esas historias suelen dejar espacios para momentos menos afortunados, en última instancia siempre se presume un final feliz. Sin embargo, la novedad de las historias de vida que se relatan en este libro radica justamente en que no son historias felices. Por eso, en la parte introductoria de la obra, su autora, María Bjerg, reconocida especialista en estudios migratorios de Argentina, propone recomponer algunas experiencias de familias cuyos vínculos se quebrantaron cuando uno de los cónyuges, por lo general el marido, decidió emigrar de Italia o España hacia el Cono Sur. El derrotero de estas familias de inmigrantes entre los siglos XIX y XX no tuvo el final más esperable, esto es, que la familia se reuniera en América, luego de que el esposo pudiera ahorrar, afincarse y acomodarse económicamente, o bien, que este regresara con ahorros para mejorar su calidad de vida en Europa. Al contrario, el reencuentro estuvo más bien marcado por la llegada de algunas mujeres que, por rumores de bigamia, decidieron afrontar solas el cruce del Atlántico sorteando las trabas judiciales y burocráticas para comprobar la veracidad de los dichos e iniciar denuncias por la ilegalidad del vínculo contraído por el esposo en Argentina. Otras en cambio, por la frustración y la miseria en la que vivían por los sueños de progreso truncado, al llegar al nuevo país, o antes de hacerlo, entablaban relaciones ilícitas con otros hombres, lo cual supuso para algunas terminar encarceladas y despojadas de sus ahorros, e incluso muertas por la violencia de sus esposos legítimos.

Con el análisis de 50 juicios por bigamia, 30 por adulterio, 30 por lesiones y cinco por uxoricidios, la historiadora indaga en cuatro capítulos todas estas "relaciones malogradas". La metodología consiste en la construcción de casos de estudio con los expedientes judiciales; pero no solamente eso, pues, como bien sostiene Bjerg, así solo se daría "una fotografia" de la situación. Por ello, reconstruye el

* Universidad Nacional de General Sarmiento, Argentina. 
contexto previo en el cual habitaron los sujetos que estudia y rastrea en otro tipo de fuentes, como, por ejemplo, en los censos nacionales y provinciales, el destino de algunos al finalizar el proceso judicial. Toda esa información es complementada con la prensa nacional y étnica, con registros parroquiales y con algunas cartas y fuentes secundarias como los códigos civiles. Su indagación se basa en la perspectiva de las emociones, un enfoque en boga en los últimos tiempos para aproximarse a las subjetividades de los actores involucrados en estas historias familiares marcadas por los conflictos. De este modo, la historiadora demuestra que las emociones no son universales ni atemporales, sino que tienen historia y deben ser analizadas en los contextos en los cuales se manifiestan.

En "La promesa, la espera y la traición", la autora reconstruye cuatro casos de desavenencias matrimoniales a partir de la migración de hombres europeos a Argentina y el incumplimiento de su compromiso con su esposa legítima. Esto los expuso a juicios de bigamia. Bjerg demuestra cómo algunos de ellos pudieron evadir la condena gracias a sus nuevas redes y contactos políticos y familiares. Otros, en cambio, debieron cumplir la condena por sus segundas nupcias ilegales y documentaron los logros de sus primeras esposas, quienes cruzaron el Atlántico para reclamar el cumplimiento de las promesas rotas: el envío de los emolumentos para migrar con los hijos, la falta de correspondencia y el envío regular de las remesas de dinero.

La otra cara de la moneda puede descubrirse en "Quebrantar los deberes sagrados", donde la autora indaga las experiencias de infidelidad de algunas mujeres inmigrantes y sus amantes. Ellas fueron acusadas de adulterio y, en la mayoría de los casos, recibieron penas de encarcelamiento. Si, además del adulterio, la esposa había resultado embarazada, era doble el crimen cometido, ya que, en ese contexto cultural y legal, "al problema del querer y del honor venía a sumarse el del linaje" (p. 56). En este capítulo, Bjerg se centra en analizar las emociones que primaban a la hora de dar sentido y dirimir esos problemas matrimoniales: la venganza, la vergüenza y la compasión. La venganza en ocasiones servía como canalizadora de la ira que pudo haber sentido el esposo al enterarse de la infidelidad; aunque tenía su parte racional, podía ser considerada como efecto del sentimiento de revancha y rabia. La vergüenza, una emoción social, muchas veces servía para contener en cuatro paredes los conflictos domésticos (violencia, adulterio, etcétera), pero que salían a relucir cuando la mujer se escapaba de su hogar con otro hombre para alejarse del matrimonio malogrado y se ponía en evidencia la conflictiva relación conyugal. Finalmente, la compasión también aparece en los relatos judiciales, como la emoción que llevaba a algunos hombres a fugarse con mujeres casadas por la vida de privaciones y de infortunios que estas experimentaban con sus maridos legítimos, ya fuera al quedarse solas en Europa, o bien cuando ya estaban en Argentina y no lograban retomar su relación conyugal como era antes de la inmigración. El hecho de encontrar una nueva vida las exponía a quebrar los deberes sagrados que les eran asignados socialmente por estar casadas y a poner en vilo el honor y la masculinidad del esposo en cuestión. 
La especialista escudriña en las fuentes judiciales, prensa étnica y nacional para reponer el entramado de violencia y de conflictos que se dirimían en ámbitos privados (habitaciones de conventillos), lugares de trabajo, o bien en altercados callejeros que involucraban la fuerza física. Las noticias periodísticas ante la violencia doméstica, que incluso en algunos casos resultó en muertes, oscilaban entre la tolerancia y la condena moral. En el derrotero judicial de las querellas, la historiadora encontró algunas resoluciones más amigables para las mujeres, donde el marido violento terminó siendo preso; sin embargo, muchas veces el esposo golpeador respaldó su actitud, motivada por la ira, en que la mujer le había sido infiel faltando a la moral y al decoro. Vale destacar que la autora muestra cómo en algunos casos, luego del enojo, las mujeres querían "salvar" a sus maridos de la cárcel porque caían en cuenta de la delgada línea que existía entre el hombre proveedor y el hombre violento. Salvo excepciones, algunas mujeres también contaban con su propio dinero, el cual terminaba siendo causante de conflictos, porque, más que gastar en ellas, tenían que utilizarlo, bajo puñetazos y golpes, para la economía familiar. Todas estas cuestiones dieron como resultado "Cuerpos (in)dóciles y odios cotidianos".

Finalmente, la autora explora dos casos de uxoricidios, forma tradicional en la época para denominar los crímenes domésticos, en "La Pasión de los celos". Con solidez, reconstruye el rumbo trágico de dos mujeres asesinadas por sus maridos. Como ambos enfrentaron juicios, y uno de ellos incluso terminó con condena fija, las fojas permiten reponer discursos de los distintos actores intervinientes. En su defensa, se deja traslucir una justificación del delito en términos morales porque las víctimas mantenían relaciones extramatrimoniales, lo cual suponía una reacción de celos que, aunque no justificaba el crimen, lo minimizaba. En el caso de un español que terminó con la vida de su cónyuge, se logró la imputabilidad del acusado porque pudieron comprobar los problemas mentales que el agresor tenía y con los que fue justificado su delito.

Lazos rotos. La inmigración, el matrimonio y las emociones en la Argentina entre los siglos XIX y XX nos devuelve una imagen aún poco conocida de la experiencia inmigratoria pese al desarrollo de la historiografía en este campo en la Argentina, del cual Bjerg forma parte. Su mayor originalidad y mérito no se agota en el tema, sino en la capacidad para desentrañar las emociones que suscita el entramado de lazos que se tejen y destejen a uno y otro lado del Atlántico. Gracias a un análisis detenido y sutil, principalmente de expedientes judiciales, este libro tiene el potencial de acercar al lector a la vida familiar y a los afectos y emociones, tanto de hombres como de mujeres, en su cotidianidad. Se puede aprender cómo y por qué la inmigración de hombres a la Argentina supuso la ruptura total de sus matrimonios y la separación familiar. Asimismo, es posible comprender los vericuetos y el funcionamiento de la justicia al conocer cómo se dirimían los altercados conyugales, pues estaban en juego las pautas sociales y culturales de la época, de acuerdo con las cuales, la mujer debía ser la garante de la honorabilidad de su familia y de la castidad, tanto en Argentina, como en Europa. Finalmente, permite 
un acercamiento a la forma en que interactuaban algunos inmigrantes con los funcionarios estatales y la justicia del nuevo país de residencia. Vale advertir que, más allá de las convenciones, que exigen límites difusos en los títulos, este estudio se refiere a casos que transcurrieron en la ciudad y provincia de Buenos Aires entre los años ochenta del siglo XIX y las primeras décadas del siglo XX.

La minuciosidad y sensibilidad de la autora ante los casos que analiza permite vislumbrar una vida familiar "transnacional" que se caracterizaba también por muertes, conflictos y desamores, matizando así la reunión familiar en términos deseables y esperables. Es un compendio de la situación de hombres y mujeres con experiencias desiguales, donde se pone en primer plano que no era lo mismo ser mujer que hombre para emprender un proyecto y la vida inmigratoria en el siglo XIX y principios del XX. Se trata de un libro que resultará atractivo para quienes se interesen por los estudios de la inmigración, la historia de la familia, la investigación sobre las relaciones y jerarquías de género, así como para estudiosos del campo de las emociones y de la historia social de la justicia. En fin, este cruce entre las historias de la inmigración y el campo de las emociones, por una parte, abre la posibilidad de profundizar sobre este tipo de investigaciones en otros grupos migratorios que llegaron al país y que no se restrinjan únicamente a la ciudad y provincia de Buenos Aires, o bien, para reconstruir su vida familiar en este tipo de fuentes que analiza Bjerg. Por otra parte, es una veta para analizar también las relaciones y las redes políticas y familiares que entablaron los inmigrantes en el país de residencia desde lo emocional. Además, hace posible indagar sobre la historización de la violencia de género y cómo se construyeron históricamente las diferencias entre hombres y mujeres

No está por demás mencionar que la obra tiene relevancia historiográfica, pues permite un acercamiento de manera menos optimista a la experiencia inmigratoria y a las emociones y subjetividades de los actores que la emprendieron. De esta manera, se cuestiona el que la inmigración fuera solamente la promesa de un ascenso social; si bien pudo haber sido así para la mayoría, también se pueden rastrear historias de olvidos, de frustraciones, de miserias, de desamores, de "lazos rotos". Por eso, la autora cumple el principal objetivo que se propone en su libro, que es mostrar cómo la inmigración transformaba los vínculos matrimoniales que terminaron con "desenlaces desventurados". En este sentido, los expedientes judiciales son centrales para su reconstrucción, pues en ellos María Bjerg rastrea y vuelve a dar voz a los alegatos de los querellantes, de los acusados, de los magistrados, de los jueces y testigos. Probablemente, hay muchos otros casos como estos que estudia Bjerg, pero, al no haberse iniciado una denuncia y un proceso penal, quedaron supeditados al entorno familiar, sin vestigios para analizarlos.

Doi: 10.17533/udea.trahs.n19a12 